Review

\title{
A Review on Waste to Energy Processes Using Microwave Pyrolysis
}

\author{
Su Shiung Lam ${ }^{1,2, *}$ and Howard A. Chase ${ }^{2}$
}

1 Department of Engineering Science, Faculty of Science and Technology, Universiti Malaysia Terengganu, 21030 Kuala Terengganu, Terengganu, Malaysia

2 Department of Chemical Engineering and Biotechnology, University of Cambridge, New Museums Site, Pembroke Street, Cambridge CB2 3RA, UK; E-Mail: hac1000@cam.ac.uk

* Author to whom correspondence should be addressed; E-Mail: lam@umt.edu.my; Tel.: +60-9668-3844; Fax: +60-9668-3326.

Received: 29 June 2012; in revised form: 6 September 2012 / Accepted: 12 October 2012 / Published: 23 October 2012

\begin{abstract}
This paper presents an extensive review of the scientific literature associated with various microwave pyrolysis applications in waste to energy engineering. It was established that microwave-heated pyrolysis processes offer a number of advantages over other processes that use traditional thermal heat sources. In particular, microwave-heated processes show a distinct advantage in providing rapid and energy-efficient heating compared to conventional technologies, and thus facilitating increased production rates. It can also be established that the pyrolysis process offers an exciting way to recover both the energetic and chemical value of the waste materials by generating potentially useful pyrolysis products suitable for future reuse. Furthermore, this review has revealed good performance of the microwave pyrolysis process when compared to other more conventional methods of operation, indicating that it shows exceptional promise as a means for energy recovery from waste materials. Nonetheless, it was revealed that many important characteristics of the microwave pyrolysis process have yet to be raised or fully investigated. In addition, limited information is available concerning the characteristics of the microwave pyrolysis of waste materials. It was thus concluded that more work is needed to extend existing understanding of these aspects in order to develop improvements to the process to transform it into a commercially viable route to recover energy from waste materials in an environmentally sustainable manner.
\end{abstract}


Keywords: waste to energy; pyrolysis; microwave; microwave pyrolysis; waste treatment; waste

\section{Introduction}

Waste materials such as waste oil, plastic, and biomass waste are being generated every year around the world. Some of these wastes are effectively collected and recovered for use as an energy source or chemical feedstock, while some are simply discarded or burned in ways that can pollute the environment. The improper disposal of these waste materials (e.g., used engine oil, PVC, and municipal solid wastes) may constitute an environmental hazard due to the presence of undesirable species such as metals, soot and polycyclic aromatic hydrocarbons (PAHs). For example, studies have reported that the high concentrations of PAHs in sewage effluents and urban runoffs are due to their contamination by waste oil [1]. Due to the difficulties associated with the contaminants in these waste materials, a large portion of the wastes are simply disposed of by landfilling. This method presents no recovery of the potential value of the waste but leads to potential environmental pollution due to considerably long decomposition times and the risk of contaminants leaking out to the surrounding environment. As such, the treatment and disposal of these wastes represents a significant challenge in the real world.

Another form of waste disposal is achieved by thermal means through incineration, which is typically used for energy recovery purposes. In this energy recovery process, waste materials are burned in furnaces to produce energy in the form of electricity and/or heat. This method can be applied to all types of hydrocarbon waste; however, it has several drawbacks. The combustion of waste results in the release of greenhouse gas such as $\mathrm{CO}_{2}$ that contributes to climate change. In addition, incineration can lead to toxic emissions that pose a direct hazard to the environmental and human health [2,3], largely due to the undesirable contaminants present in both the waste (e.g., soot or particulates containing PAHs, metals from engine oil) and the flue gas emitted from the incineration process (e.g., fly ash, oxidised compounds such as polychlorinated dibenzodioxins). On the whole, incineration recovers only the calorific value of the waste and does not allow for the recovery of any of the chemical value of the waste, and thus this method is becoming increasingly impracticable due to concerns of greenhouse gas release and environmental pollution associated with toxic emissions. Furthermore, the cleaning of the flue gases produced is complex and expensive due to strict regulations on atmospheric emissions. Therefore, research has moved towards developing a better solution, from an environmental and economic standpoint, by thermally reprocessing the waste materials into more useful energy forms using thermal conversion processes.

Thermal conversion involves the use of a wide range of thermal decomposition processes such as pyrolysis and gasification to decompose waste materials into smaller molecules that can be used as energy source or inputs for the synthesis of new materials, e.g., hydrocarbon wastes are decomposed to produce syngas $\left(\mathrm{H}_{2}+\mathrm{CO}\right)$; the syngas can be used as a fuel directly, or converted into liquid fuel through the Fischer-Tropsch process [4]. In these processes, waste materials are heated and cracked in the absence of oxygen into smaller molecules. While thermal conversion shows advantages in dealing 
with a wide variety of wastes of a hydrocarbon nature (e.g., used tyres [5] and plastic waste [6]), and recovering both the energy and chemical value of the wastes [7], it is an energy intensive process that usually requires a large scale operation coupled with a capital intensive plant [8]. Although thermal conversion techniques have recently shown potential as an environmentally friendly waste disposal method $[9,10]$, such practice is yet to become popular.

Pyrolysis is a thermal process that heats and decomposes a substance in an environment from which oxygen is excluded. It can be used as a thermal conversion technique for hydrocarbon wastes, where the waste materials are cracked to produce hydrocarbon oils, gases, and char. The process can be optimised to maximise production of any of these constituents by altering parameters such as process temperature and reactant residence time [11], e.g., a high temperature and high residence time promotes the production of gases; a high temperature and low residence time (termed "flash pyrolysis") results in increased yield of condensable products, and a low temperature and heating rate leads to increased char production [12] or to no chemical reactions taking place at all. The wide variety of pyrolysis products indicates that the products may need to be separated and purified before they can be used further; this can usually be achieved through the use of existing distillery and refinery facilities, however, in some cases more advanced techniques are required for the separation, e.g., the use of material separation agents for the separation of azeotropes in pyrolysis oil product (termed "azeotrope or extractive distillation").

The review focuses on the development of an emerging pyrolysis technology termed microwave pyrolysis employed for efficient treatment and energy recovery from various waste materials, either as a disposal route to convert waste materials to petrochemical products suitable for use as a fuel, or as an integrated treatment process for the production of raw chemical feedstock for future reuse. This technology is expected to offers a number of advantages over other conventional pyrolysis processes and makes a practical contribution to the challenge of redesigning human behaviour for sustainability.

\section{Current Pyrolysis Techniques for Waste to Energy Application}

Pyrolysis techniques have been developed as an alternative to treat and convert waste materials to products suitable for use as a potential energy source $[10,13,14]$, though the use of this technology is not currently widespread. The main advantage of pyrolysis is that it has the potential to recover both the energy and chemical value of the waste by generating potentially valuable products from the pyrolysis process. The oil and gaseous products demonstrated a high calorific value, and the char produced can be used as a substitute for carbon black. In particular, the gaseous product is of considerable interest due to its potential as a source of hydrogen fuel. Other advantages compared with steam reformation processes include negligible production of toxic oxidised species (e.g., dioxins, NOx) [15,16], less energy consumption and the production of a disposable solid waste (char) [17]. Due to its ability to produce potentially valuable products, vigorous efforts have been made to perfect the pyrolysis process and techniques for energy recovery from waste materials, in addition to offering an alternative solution to disposal of the waste by incineration.

For the past two decades, research on pyrolysis processes has been conducted using several types of equipment heated by conventional heating source (e.g., an electric or gas heater), namely: fluidised bed reactors, rotating cone reactors, melting vessels, blast furnaces, tubular or fixed bed reactors $[14,18]$. 
For example, the institutions in Spain and Turkey use tubular and fluidised bed reactors heated by either electric furnaces, ovens, or heaters [5,19-21], whereas the Korean institutions employ stirred batch reactors heated by either jacketed electric heaters [22], autoclaves, or molten salt baths [23]. These types of equipment were used in a manner where the thermal energy is externally applied to the reactor and heats all the substances in the reactor including the evolved pyrolysis-volatiles, the surrounding gases, and the reactor chamber itself. In this case, energy is not fully targeted to the material being heated and this results in significant energy losses in terms of the energy efficiency of the whole process. Nevertheless, several of these processes have been developed into a pilot plant scale despite their limited energy efficiency [24].

Song et al. [9] have recently examined the use of electric arc heating to pyrolyse waste oil. The electric arc pyrolysis employs a different heating mode compared to conventional electric-heated pyrolysis. An electric arc cell or generator was used to generate a momentary electric discharge for pyrolysing the waste oil in order to produce high-value fuel gases (e.g., hydrogen and acetylene) and "usable" carbonaceous residue. It is considered a flash pyrolysis process whereby the waste material is rapidly heated to $1300-1500{ }^{\circ} \mathrm{C}$ for $0.01-1 \mathrm{~s}$, producing incondensable gases and carbonaceous residues as the pyrolysis products. Although this technique shows potential as a waste-to-energy method, such technique should be investigated further due to concerns over the presence of undesirable species (e.g., PAHs, metals, and mixed oil-additive polluted residues) in the pyrolysis products [25].

It was established that current pyrolysis techniques (mostly conventional electric-heated pyrolysis processes), when compared with incineration and steam reformation processes, offer a number of advantages and shows excellent potential for waste-to-energy applications. However, such practices possess limitations and at present there are still problems associated with these pyrolysis techniques. The low thermal conductivity of some waste materials (e.g., engine oil with a thermal conductivity ranging from 0.15 to $0.30 \mathrm{~W} / \mathrm{m} . \mathrm{K}$ ) often necessitates a long processing time due to the low rate of heat transfer within the material in order for pyrolysis to occur. Furthermore, in conventional electric-heated pyrolysis, the waste material is heated by an external heating source which also heats all the substances in the heating chamber including the evolved pyrolysis-volatiles and the chamber itself. This results in significant energy losses and can also promote undesired secondary reactions of the evolved pyrolysis-volatiles that lead to formation of toxic compounds (e.g., PAHs) [26] and increased production of char [17], which can cause problems such as coking on the reactor wall and fouling of the system with particulates. Moreover, the uneven distribution of heat produced in some conventional pyrolysis processes has led to poor control over the heating process; as a result, the final fractions obtained from the pyrolysis are often varied and critically depend on the actual process conditions applied to the waste material [27]. It was also found that the existing literature is limited to pyrolysis performed in batch or semi-batch operation in which the waste material was added initially to a batch system before being subjected to pyrolysis. Limited information is therefore available concerning the characteristics of the pyrolysis of the waste material (e.g., the influence of key process parameters on the product distribution) when the pyrolysis is performed in a continuous operation. Owing to the limitations, inconsistent performance, and uncertainties shown by conventional pyrolysis, it is important to find an alternative pyrolysis technique to rectify these deficiencies in order to ensure better performance and control of the pyrolysis process as well as the production of more desirable pyrolysis products. 


\section{Microwave Pyrolysis}

Microwave pyrolysis is a relatively new process and was initially developed by Tech-En Ltd. in Hainault, UK [28,29]; this thermal treatment in a microwave-heated bed of particulate-carbon has been shown to be an effective method of recovering and recycling chemicals present in troublesome wastes such as plastic waste, sewage sludge, and coffee hulls [7,12,30,31]. In this process, waste material is mixed with a highly microwave-absorbent material such as particulate-carbon, which absorbs microwave energy to generate sufficient thermal energy to achieve the temperatures required for extensive pyrolysis to occur. As a result of microwave heating, the waste material is thermally cracked in the absence of oxygen into smaller molecules. The resulting volatile products are either recondensed into an oil product (termed "pyrolysis-oil") or collected as incondensable gaseous products (termed "pyrolysis-gases") of different compositions depending on the reaction conditions.

\subsection{Principles behind Microwave Pyrolysis}

\subsubsection{Introduction to Microwave Heating}

Microwave heating is performed at frequencies of $915 \mathrm{MHz}(\lambda=\sim 33 \mathrm{~cm})$ and $2.45 \mathrm{GHz}(\lambda=\sim 12 \mathrm{~cm})$ as specified by international agreement [32]. The technique was introduced after the Second World War following the development of the magnetron valve (a very high power source of microwaves with exceptional efficiency) as an efficient processing tool for heating. The heating occurs when the magnetron generates electromagnetic radiation that causes dipolar molecules to attempt to rotate in phase with the alternating electric field created by the electromagnetic radiation. Resistance to this rotation on the molecular level results in friction between the molecules and causes heat to be generated [33]. This heating method has many advantages over conventional thermal heating methods.

Conventional thermal heating usually employs an external heating source to transfer heat to material through a surface; as a result, heating is governed by the temperature of that surface as well as limited by the physical properties of the materials being heated, such as density, heat capacity, and thermal diffusivity of the material. In contrast, microwave heating constitutes a unique way of heating where the heating effect arises from the interaction of electromagnetic wave with the dipoles within the material being heated. In general, three mechanisms are responsible for the microwave heating resulting from the interactions mentioned above (see Section 3.1.2). By such heating mechanisms, heat is generated within the material rather than from an external source, thereby giving a more efficient heating process compared to conventional surface heating with respect to even distribution of heat and easier control over the heating. In addition, high temperatures and heating rates can be obtained through microwave heating [7], and it shows remarkably high conversion efficiency of electrical energy into heat $(80 \%-85 \%)[15]$.

\subsubsection{Microwave Heating Mechanisms}

Microwave heating is classified as an electric volumetric heating method. Other heating methods in this category include conduction and induction heating operating at frequency ranges of $0-6 \mathrm{~Hz}$ and $50 \mathrm{~Hz}-30 \mathrm{kHz}$, respectively; these heating methods were performed by passing a current through the 
workload to induce electric power $\left(I^{2} R\right)$ heating. Ohmic heating, which operates at the frequency range in between conduction and induction heating, is also classified into the same category and this heating method operates with the same principle as the former methods. Radio frequency heating, operating at a frequency range from 1 to $100 \mathrm{MHz}$ (often at $27.12 \mathrm{MHz}$ ), is included in this category and this heating method is usually used for workloads that give a high resistivity when placed between electrodes. A typical electromagnetic spectrum with examples of applications performed by different electric volumetric heating methods at various frequency ranges is presented in Figure 1.

Figure 1. Typical electromagnetic spectrum with examples of applications performed at different frequency ranges [32].

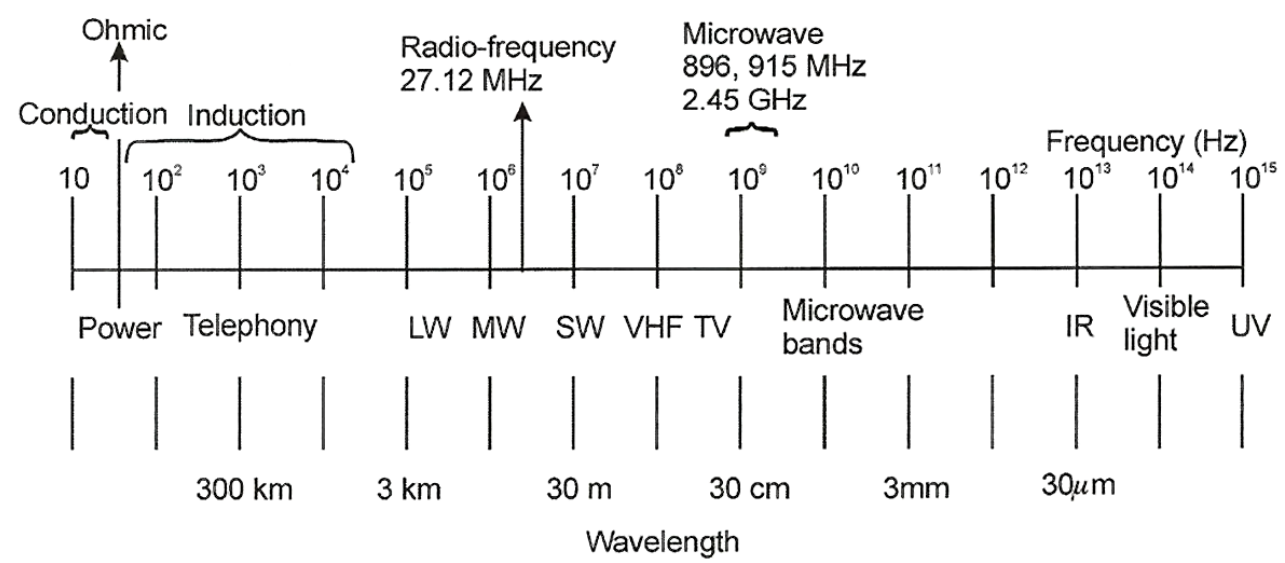

The principles and theories behind microwave heating are well understood and available in several textbooks [32,34]. In general, there are three mechanisms by which materials are heated in a microwave field. These mechanisms arise from the displacement that charged particles in the material undergo when they are subjected to the microwave radiation and could be summarised as follows:

i. Dipole reorientation (polarization) — substances containing polar compounds are mainly heated via this mechanism when they are subjected to microwave radiation. When subjected to a microwave field, the electrons around the nuclei (electronic polarization) or the atomic nuclei themselves (atomic polarization) are displaced from their equilibrium position, forming induced dipoles. In some materials (e.g., water) permanent dipoles exist due to the asymmetric charge distribution in the molecule. The induced or permanent dipoles tend to reorient under the influence of the changing or alternating electric field. The chemicals bonds of induced or permanently polarized molecules are realigned in the fluctuating field. This realignment occurs trillions of times each second [35] and results in friction between the rotating molecules, and thus causes heat to be generated within the whole volume of material.

ii. Interfacial or Maxwell-Wagner polarization - this polarization arises from a charge build-up in the contact areas or interfaces between different components in heterogeneous systems. The polarization is created due to the difference in conductivities and dielectric constants of the substances at the interfaces. The accumulation of space charge leads to field distortions and dielectric loss that contribute to the heating effects.

iii. Conduction mechanism-when an electrically-conductive material is subjected to electromagnetic radiation, electric currents are produced where the charged particles or carriers 
(electrons, ions, etc.) in the material move through the material under the influence of the externally applied electromagnetic field forming conducting paths. As these electric currents flow within the structure of the materials, which in most cases have a relatively high electrical resistivity, the material is heated because the power generated by the forced flow of electrons is dissipated as heat.

The extent to which a material heats up when subjected to electromagnetic radiation (e.g., microwave radiation) is mainly determined by its dielectric properties, which depends on two key parameters: the dielectric constant $\left(\varepsilon^{\prime}\right)$ and the dielectric loss factor $\left(\varepsilon^{\prime \prime}\right)$. The dielectric constant expresses the ability of a material to be polarized by an electric field by determining how much of the electromagnetic energy is reflected and how much is absorbed, whereas the dielectric loss factor quantifies the efficiency with which the electromagnetic energy is converted to heat. The ratio of dielectric loss factor to dielectric constant defines the dielectric loss tangent or dissipation factor of a material:

$$
\tan \delta=\frac{\varepsilon^{\prime \prime}}{\varepsilon^{\prime}}
$$

The dielectric loss tangent of a material determines its ability to absorb and convert electromagnetic energy into thermal energy at a given temperature and frequency. In microwave heating process, this parameter is an important factor that determines the heating rate and final temperature that can be reached by a material heated by microwave radiation [36]. Thus, a material with a moderate value of $\varepsilon$ ' and a high value of $\varepsilon$ " (and so a high value of $\tan \delta$ ) is considered as a good microwave receptor with high capability in converting electromagnetic energy into thermal energy. Typical materials that exhibit good dielectric properties with a high value of $\tan \delta$ are carbon materials and inorganic oxides [37], whereas materials such as plastics are considered as 'transparent' to microwaves because they do not possess a sufficiently high dielectric loss factor ( $\varepsilon$ ") to allow for dielectric heating [35].

\subsubsection{Microwave Heating of Carbon Materials and its Application in Pyrolysis Processes}

Microwave heating combined with the use of carbon material has been applied in the processing and treatment of certain materials. Carbon materials are good microwave-absorbents that show high capacity to absorb and convert microwave energy into heat; the dielectric loss tangent ( $\tan \delta$ ) of carbon materials such as charcoal, carbon black, and activated carbon, which range between 0.1 and 0.8 , is either comparable to or higher than the $\tan \delta$ of distilled water $(\sim 0.1)$, which is commonly known as a very good microwave-absorbent [35]. Thus, carbon materials can be used as an effective microwave-absorbent to heat substances that are transparent to microwaves radiation. The use of carbon materials combined with microwave heating has been applied to soil remediation processes and catalytic heterogeneous reactions [35].

Microwave heating combined with the use of carbon materials has recently been applied in pyrolysis processes to treat or process a variety of materials, e.g., biomass [12,38], coal [39,40], oil shale [41], glycerol [42] and various organic wastes [28]. In general, these materials are poor microwave-absorbent that are either transparent to microwaves or with poor dielectric properties, therefore they requires heating by contact with materials with high microwave absorbency (e.g., carbon materials [12,38,41-43] or metal oxides [39]) to achieve higher temperatures in order for extensive pyrolysis to occur. Carbon materials are usually used rather than metal oxides due to their 
low cost and ease of acquisition [35]. This type of pyrolysis (termed "microwave pyrolysis"), which involves the use of microwave radiation as an indirect heat source combined with the use of carbon materials as the microwave receptor to directly heat and pyrolyse the materials, is known to offer additional advantages over conventional pyrolysis techniques (see Section 3.2).

The heating of carbon occurs when sufficient microwave energy is absorbed by the carbon particles and converted to thermal energy by dipole reorientation and ionic conduction (the 1st and 3rd mechanism described in Section 3.1.2), and thus causing heat to be generated within the particles [44]. A detailed study of the ionic conduction mechanism has been presented and discussed by Liu et al. [45]. The group led by Menendez has recently demonstrated that the microwave heating of carbon materials also occurs via the combination of Maxwell-Wagner polarization and conduction mechanism (the 2nd and 3rd mechanisms described in Section 3.1.2) [35]. The authors claimed that a current travelling in phase with the electromagnetic field is induced within the carbon material when it is subjected to microwave radiation. As a result, the $\pi$-electrons (i.e., charged particles that are free to move in a limited region within the material) in the carbon material are displaced from their equilibrium positions and this leads to dielectric polarization. The positive charges are displaced toward the field and negative charges are shifted in the opposite direction under the influence of dielectric polarization. This creates an internal electric field which reduces the overall field within the carbon material itself. As the $\pi$-electrons are repeatedly shift from one position to another under the influence of the changing or alternating electric field, this leads to a charge build-up within the carbon material. The power generated by the forced flow of electrons and the accumulation of charge within the carbon material due to Maxwell-Wagner polarization (which leads to field distortions and dielectric loss) result in energy being dissipated as heat and thus contributing to the heating effects. Figure 2 shows a schematic representation of the microwave heating of carbon material proposed by the Menendez group.

Figure 2. Schematic representation of microwave heating of carbon material [46].

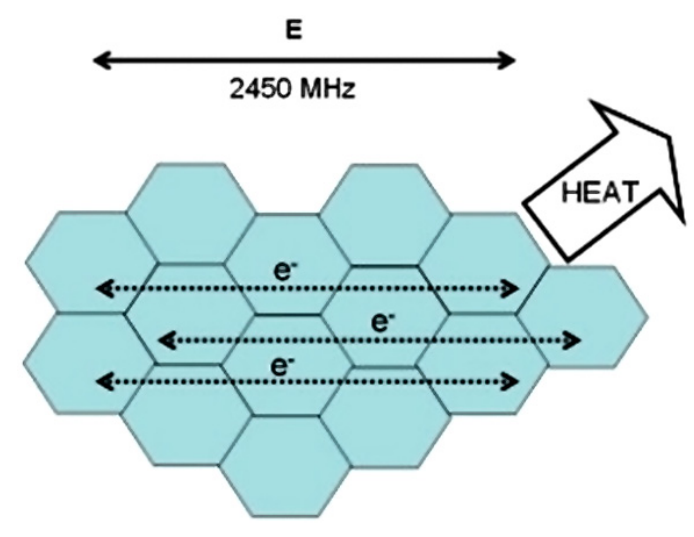

In addition, these authors demonstrated that an additional phenomenon may occur in microwave heating of carbon materials. They claimed that in some cases the kinetic energy of some $\pi$-electrons in the carbon material may increase to a level that allows the $\pi$-electrons to jump out of the carbon, resulting in the ionization of the surrounding atmosphere [35]. This phenomenon is perceived as sparks or an electric arc at a macroscopic level, but it is considered as hot spots or plasmas at a microscopic level. The generation of sparks or hot spots may have effects on the reaction pathways that occur in processes that incorporate the microwave heating of carbon. 


\subsection{Microwave-Heated Pyrolysis Compared to Conventionally-Heated Pyrolysis}

Microwave heating is currently employed for energy transfer in various industrial, technological and scientific processes and applications. Industrial microwave heating systems have been developed for a variety of applications in food industry, e.g., continuous baking, vacuum drying, tempering and thawing, pasteurisation, and sterilisation [32]. In addition, this technology has long been employed in the rubber and polymer industries for applications such as rubber vulcanization, polymerization or curing of resins and polymers by elimination of polar solvents [35], but there is a growing interest for its potential use as a heat source in pyrolysis processes (termed "microwave pyrolysis"), particularly in the treatment of various waste-streams.

It has been reported that microwave-heated processes showed advantages over their conventionally heated counterparts (e.g., conventionally heated oil baths, conventional electric-resistance heated systems such as electric-heated mantles and furnaces) in promoting clean, fast and high yielding chemical reactions that occur during the thermal processes [47,48]; the chemical reactions refer mainly to organic reactions, though the interpretation to some extent is also relevant to other thermal processes involving organometallic and inorganic compounds, and materials such as ceramics and polymers; in addition, the reaction is described as "clean" due to its low hold-up of potentially dangerous intermediates and its significantly lower production of contaminants. The authors claimed that these beneficial effects could be attributed to the lower thermal inertia and faster response (e.g., increasing reaction rates by reducing activation energies) exhibited by microwave heating methods. Despite the various studies to establish the difference between microwave-heated and conventionally-heated processes, Strauss and Rooney [49] have recently demonstrated that the claims are valid only when comparably rapid heating cannot be obtained by conventional heating.

Although reports that microwave-heated reactions typically proceed faster, more cleanly, and in higher yields than their conventionally heated counterparts have widely appeared in literature [50,51], the explanation behind such findings has been interpreted as mostly speculations due to the lack of compelling scientific evidence [52,53]. Some workers had tried to attribute non-thermal effects as the source of the faster, cleaner and higher yielding reactions occurred in microwave-heating processes [31,54], however a number of studies have demonstrated that the vast majority of the reactions proceed thermally under microwave-heated conditions [55,56]. These studies indicated that the reactions occurred under microwave-heated conditions should produce identical outcomes to those occurred under conventionally-heated conditions if their thermal profiles are identical [57]. Nevertheless, it can be established from the many literature reports on microwave-heated processes that microwave heating is generally accepted to have an influence in promoting and accelerating certain chemical reactions due to the advantageous features such as fast heating rates, high power density, even heating, and good heating control.

Despite the vigorous debate about the difference between microwave-heated and conventionally-heated processes, it should be noted that the discussion in the previous paragraph focuses mainly on materials heated directly by microwave radiation in order to produce physicochemical changes. In contrast, this review describes the work performed to study a microwave-heated process that employs a different approach by using microwave radiation as an indirect heat source to heat and pyrolyse waste materials. In this microwave-heated process (termed "microwave pyrolysis"), waste material is pyrolysed by contact 
with a bed of particulate-carbon heated by microwave radiation. The highly microwave-absorbent particulate-carbon absorbs enough microwave energy and heats up initially to achieve the desired temperature for pyrolytic thermal cracking, and subsequently crack the waste material to produce a variety of different products. Thus, this microwave pyrolysis process, which involves the pre-heating of carbon followed by the transfer of heat to the waste material in order for cracking to occur, may present a different concept (e.g., heating mechanism) and produce a different outcome as to the microwave-heated processes described in the previous paragraph.

It was established that microwave pyrolysis offers a number of advantages over conventional pyrolysis techniques. The use of microwave radiation as a heat source is known to offer additional advantages over traditional thermal heat sources [58,59], and the combination of carbon-based material and the novel use of microwave heating in pyrolysis processes is of increasing interest as reflected by considerable recent research reported in the literature [30,42]. Microwave radiation provides a rapid and energy-efficient heating process as compared to conventional technologies (e.g., 50\% more efficient than heating by natural gas, steam) [60]. The diffuse nature of the electromagnetic field allows microwave heating to evenly heat many substances in bulk [61], without relying on slower and less efficient conductive or convective techniques. In addition, microwave heating offers a reliable, low cost, powerful heat source, with modern equipment operating at over $90 \%$ conversion efficiencies of electricity into thermal energy [15]. Thus, the use of microwave radiation as a heat source offers an improved uniformity of heat distribution, excellent heat transfer, and provides better control over the heating process. Other advantages compared with conventional heating techniques (e.g., electrical furnace) include fast internal heating [61], higher power densities and the ability to reach high temperatures at faster heating rates [7], higher heating efficiency [58], facilitating increased production speeds and decreased production costs [62]. The process can be physically gentle, allowing for a wide variety of applications in diverse fields [58,60]; increased process yield, environmental compatibility, and savings in process time are among the advantages reported on microwave processing of materials [63]. Furthermore, the process can be developed at a variety of scales that allows for on-site treatment of waste material, and thus reducing the additional costs needed for the transport of waste material to a specific treatment centre or waste processing plant.

Microwave radiation can be used to directly heat substances if they exhibit good dielectric properties; substances that are 'transparent' to microwaves (e.g., plastics), or with poor dielectric properties (e.g., engine oil) necessitate the introduction of an appropriate intermediate microwave receptor. It was revealed that the use of carbon-based materials (e.g., particulate-carbon, char produced from pyrolysis) as the microwave receptor offers a number of advantages over conventional pyrolysis techniques. Carbon-based materials are good microwave-absorbents [37] that can be used to heat neighbouring substances (particularly those that are transparent to microwaves) to high temperatures at a fast heating rate by microwave radiation [38,61,64]. In addition, the use of carbon-based materials as a reaction bed provides a highly reducing chemical environment, which removes oxygen functionalities from the treated substances and decreases the formation of undesirable oxidised species during the pyrolysis $[7,44]$. Short heat transfer distances, the enveloping nature of the well-mixed carbon bed, and small particle size of the carbon materials employed (with corresponding large surface area) make this an efficient method of heat transfer. Furthermore, energy is targeted only to microwave receptive materials and not to gases within the heating chamber or the chamber itself. It can promote certain chemical reactions 
in a way that is not possible in conventional processing by selectively heating the reactants, leading to a more uniform temperature profile and improved yield of desirable products $[30,37,59,60]$.

Despite the many advantages shown by microwave pyrolysis, it should be noted that microwave radiation presents an additional hazard over traditional heating methods, although this is easily contained within an appropriate Faraday cage. Also, using microwaves places limits on which materials can be used in the construction of a reactor and its design. In particular, metal should be avoided other than to contain the microwaves, as the presence of metal can generate arcing that may cause damage to the microwave equipment.

A Case Study Comparison between Microwave-Heated and Conventional Electric-Heated Pyrolysis of Waste Oil

Table 1 compares the results obtained using microwave pyrolysis process to those of waste oil pyrolysis processes heated by conventional electric heating either using waste oil on its own or in the additional presence of coal, scrap tyres, or zeolite and alumina catalysts. The use of the microwave-heated bed of particulate-carbon, compared to the other methods of operation, seemed to have a beneficial effect in cracking the waste oil to produce higher amounts of condensable products (termed "pyrolysis-oil"). In addition, the examination of the hydrocarbon composition of the pyrolysis-oil revealed that waste oil was thermally cracked to mainly $\mathrm{C}_{5}-\mathrm{C}_{18}$ hydrocarbons (Table 1 ) compared to the heavier $\mathrm{C}_{19}-\mathrm{C}_{35}$ hydrocarbons produced in conventional electric-heated pyrolysis [5,10,22]. These results suggest that cracking reactions are enhanced through the use of a microwave-heated bed of particulate-carbon in the experimental set-up, transforming the waste oil into (greater amounts of) pyrolysis-oil comprising higher amounts of lighter hydrocarbon components.

Table 1. Comparison of product yield (wt\%) in waste oil pyrolysis processes heated with different media, and driven by microwave heating and conventional electric heating (wt $\%$-weight percentage).

\begin{tabular}{|c|c|c|c|}
\hline Type of waste oil pyrolysis & Char & Pyrolysis-gases & Pyrolysis-oil \\
\hline Microwave heating with particulate-carbon [65] & 7 & 8 & 85 \\
\hline Electric heating (only waste oil) $[10,19,27]$ & $3-13$ & $28-60$ & $34-80$ \\
\hline Electric heating with coal $[66]$ & $35-50$ & $19-40$ & $21-39$ \\
\hline Electric heating with scrap tires [5] & $16-21$ & $9-10$ & $67-72$ \\
\hline Electric heating with catalyst (zeolite,alumina) [67] & N.R ${ }^{a}$ & N.R. & $36-42$ \\
\hline Carbon components in pyrolysis-oil & $\mathrm{C}_{5}-\mathrm{C}_{18}$ & \multicolumn{2}{|l|}{$>\mathrm{C}_{18}$} \\
\hline Microwave heating with particulate-carbon [65] & $87 \mathrm{wt} \%$ & \multicolumn{2}{|c|}{$7 \mathrm{wt} \%\left(\mathrm{C}_{19}-\mathrm{C}_{30}\right)$} \\
\hline Electric heating by jacketed electric heater [22] & $19 \mathrm{wt} \%$ & \multicolumn{2}{|c|}{$81 \mathrm{wt} \%\left(\mathrm{C}_{19}-\mathrm{C}_{35}\right)$} \\
\hline Electric heating by electric furnace $[10]^{\mathbf{b}}$ & $45 \mathrm{wt} \%$ & \multicolumn{2}{|c|}{$55 \mathrm{wt} \%\left(\mathrm{C}_{19}-\mathrm{C}_{29}\right)$} \\
\hline Electric heating by electric oven $[5]^{\mathbf{b}}$ & $65 \mathrm{wt} \%$ & \multicolumn{2}{|c|}{$35 \mathrm{wt} \%\left(\mathrm{C}_{19}-\mathrm{C}_{28}\right)$} \\
\hline
\end{tabular}

Lam et al. [65] claimed that the different product compositions can be attributed to the use of the microwave-heated carbon bed in the experimental set-up, and the different heat distributions present during microwave pyrolysis. In microwave pyrolysis, the applied microwave radiation is targeted to 
and heats mainly the microwave-receptive particulate-carbon, creating a localized reaction 'hot zone' in which the added waste oil becomes totally immersed, providing excellent heat transfer and cracking capacity to crack the waste oil $\left(\mathrm{C}_{11}-\mathrm{C}_{40}\right.$ hydrocarbons) to mainly $\mathrm{C}_{5}-\mathrm{C}_{18}$ hydrocarbons that can be re-condensed into pyrolysis-oil. The $\mathrm{C}_{5}-\mathrm{C}_{18}$ hydrocarbons, together with other cracked hydrocarbons, then vaporise as pyrolysis-volatiles, leave the hot carbon bed, and move into the vapour zone (the space above the carbon bed in the reactor) before being driven out of the reactor by the $\mathrm{N}_{2}$ purge gas. The authors suggested that the pyrolysis-volatiles in the vapour zone were less likely to undergo further secondary reactions (e.g., secondary thermal cracking, carbonization) to form incondensable pyrolysis-gases and chars as there may not be enough thermal energy to supply the endothermic enthalpy to drive the secondary reactions. This is different than in the case of conventional electric heating from which the thermal energy is externally applied to the reactor and heats all the substances in the reactor including the evolved pyrolysis-volatiles, the surrounding gases, and the reactor chamber itself. This suggests that the pyrolysis-volatiles in conventional heating, being in contact with the hot surrounding gases and the walls of the reactor chamber, are likely to encounter a reaction 'hot zone' where more thermal energy is present in order for secondary reactions to occur. As a result, the pyrolysis-volatiles under these conditions are likely to undergo more secondary reactions than occur during microwave heating. In the former process, the hydrocarbon components in the pyrolysis-volatiles are further cracked to incondensable, lighter hydrocarbons $\left(\mathrm{C}_{1}-\mathrm{C}_{4}\right.$ hydrocarbons $)$ via secondary thermal cracking reactions, some of which are further transformed into chars via tertiary cracking or carbonization reactions. This leads to higher yields of both pyrolysis-gases and char residues and lower yield of pyrolysis-oil. Similar differences between conventional and microwave pyrolysis have also been observed during the treatment of other types of waste $[62,68]$. Other possible explanations that have been proposed to account for this difference include the microwave heating process itself, which has been shown to produce different products from conventional heating when all other factors are held equal $[59,62]$, and the creation of free elections on the surface of the carbon particles as a result of microwave-induction, which may influence the reaction pathway [7].

\subsection{Energy Recovery}

Vigorous efforts have been made to estimate the energy recovery in microwave pyrolysis of waste materials [65,69-72]. The estimate provides a useful measure of the energy efficiency of the process, which is an important factor that determines the viability of this type of pyrolysis process, especially in scaling and optimising the design and operation to the commercial level. While this information has been revealed in microwave pyrolysis studies of several wastes, it was found that the existing literature is limited to pyrolysis performed in batch or semi-batch operation in which the feedstocks were added initially in one batch before being subjected to pyrolysis. Limited information is available concerning the energy balance in the pyrolysis that is performed in continuous operation.

It was revealed from these studies that microwave pyrolysis process is capable of recovering pyrolysis products (e.g., hydrocarbon oils) whose calorific value are many times greater than the amount of electrical energy used in the operation of the process, showing both a positive energy ratio (energy content of hydrocarbon products/electrical energy supplied for microwave heating) and a high energy output. For example, Lam et al. [65] have recently demonstrated through their studies on 
microwave pyrolysis of waste oil that the pyrolysis can be performed in a continuous operation, and the pyrolysis apparatus described is capable of treating waste oil with a positive energy ratio of 8 and a net energy output of $179 \mathrm{MJ} / \mathrm{h}$. In particular, the oil product showed significantly high recovery $(\sim 90 \%)$ of the energy content of the waste oil. The authors also suggested that the favourable situation would be even more apparent during the operation of pilot or industrial scale equipment in which attempts to improve heat integration and recovery have been implemented.

However, it should be noted that the high energy recovery ratios observed in these pyrolysis studies involve the assumption that the only energy input of the process is the electrical energy used in the pyrolysis reactor. In practice lower energy ratios would be realised in which additional energy inputs have been taken into account, including the energy needed for the collection and transport of waste materials to the processing plant, and for the refining of the pyrolysis products (e.g., hydrocarbon oils) if they need to be further processed to produce a gas or liquid fuel.

Overall, it was established that microwave pyrolysis process show high recovery $(60 \%-80 \%)$ of the energy input to the system (e.g., electrical energy input plus the calorific value of the added waste material) $[65,69,70,72]$. The recovered energy in the form of oil and gaseous products can be potentially used as a fuel source, e.g., on-site generation of electrical energy to power the microwave pyrolysis system. Furthermore, inclusion of heat integration and recovery systems to recover energy loss from the pyrolysis reactor (e.g., insulating the reaction vessel) would further increase the amount of energy that can be recovered from the system. The review on the existing literature indicates that the microwave pyrolysis method may be an energetically viable means of recycling waste materials into useful pyrolysis products, in addition to a disposal method for the waste.

\section{Application of Microwave Pyrolysis in Waste to Energy Processes}

In view of the many advantages shown by microwave pyrolysis, studies have been performed to investigate the possible development of microwave pyrolysis process for efficient treatment and recovery of potentially valuable hydrocarbon feedstocks from waste materials. The distinct advantages shown by microwave pyrolysis (see Section 3.2) may lead to the potential for the greater production of desirable pyrolysis products, such as gaseous hydrocarbons and liquid hydrocarbon oils that can potentially be used as a fuel or chemical feedstock, while at the same time serving the purpose of recycling and disposing of waste materials. In view of that, the aim of the pyrolysis process would be to obtain valuable products that can be further used in other chemical processes and should demonstrate a commercial opportunity rather than a problem for the disposal of waste material. Thus, research on microwave pyrolysis processes of waste materials has always concentrated effort on clarifying the variation of product spectra with the nature of the load and the process conditions.

So far there has not been a consensus on what are the main products produced during the microwave pyrolysis of waste materials. In fact, there have been many explanations for the differences observed in the experiments conducted by different researchers, although some researchers have managed to obtain somewhat similar product yields. In general, three classes of product are obtained from the pyrolysis, that is: gases, oils, and char. Table 2 shows an example of the different yields of products obtained by different sets of researchers investigating energy recovery from microwave pyrolysis of waste materials. 
Table 2. Product yield $(\mathrm{wt} \%)$ from microwave pyrolysis of waste materials for energy recovery.

\begin{tabular}{llll}
\hline Research & Gases & Oil & Char \\
\hline Waste automotive engine oil [65] & 8 & 85 & 7 \\
Plastic waste [7] & $19-21$ & $79-81$ & 0 \\
Sewage sludge [73,74] & $36-63$ & $2-8$ & $30-60$ \\
Used car tyre [75] & 10 & 50 & 40 \\
\hline
\end{tabular}

In addition to the differences in product yield, varied product spectra were also found in the different studies. Domínguez et al. [74] and Zuo et al. [73] obtained high yields of syngas $\left(\mathrm{H}_{2}+\mathrm{CO}\right)$ and low yields of $\mathrm{CO}_{2}$ and $\mathrm{CH}_{4}$ in their studies on microwave pyrolysis of sewage sludge. In contrast, Lam et al. [65,71] reported high yields of condensable oil product containing substantial concentrations of light aliphatic and aromatic hydrocarbons in their microwave pyrolysis studies of waste oil, but with a comparatively lower production of gaseous product that contains light aliphatic hydrocarbons and syngas. The similarities and differences in these studies were postulated to be mainly due to the influence of operating or experimental conditions (i.e., temperature, heating source, and pressure) and the nature of the load (i.e., chemical composition and source).

However, toxic metals were surprisingly found to be present in the oil fractions following condensation of the pyrolysis products from microwave pyrolysis of certain wastes such as waste oil [76] and oil-contaminated drill cuttings [33]. According to the authors, metals (e.g., $\mathrm{Pb}, \mathrm{Fe}, \mathrm{Cu}$ and $\mathrm{Ni}$ ) are mainly present in the oils as metallic compounds; these compounds would turn into volatiles during pyrolysis processes at a reaction temperature of $600{ }^{\circ} \mathrm{C}$ and above. In addition, some metals (e.g., V, Cd) are condensed (accumulated) on the particulate matter produced during the process [76]. As a result, the metals condensed on the particulate matter and the metallic compounds (depending on their volatility) are likely to escape from the pyrolysis chamber with the other gaseous products during the pyrolysis process, causing the formation of undesired oil products containing toxic metals. As a result, efforts are being made to incorporate additional processes such as hot gas cleaning and previous demetalisation of waste materials in order to obtain oil products that are free of metals.

Toxic semi-volatile PAH compounds such as naphthalene, acenaphthylene, phenanthrene, anthracene, and pyrene were also detected in the pyrolysis products from microwave pyrolysis of waste oil $[65,76]$ and sewage sludge [77]. Thus, these studies imply that further investigation is needed to perfect the pyrolysis process conditions in order to improve the production of valuable pyrolysis products whilst controlling the formation of potentially toxic compounds described above. Some of the applications of microwave pyrolysis in the treatment and energy recovery from waste materials are further presented and discussed in the following Sections (4.1-4.5).

\subsection{Waste Automotive Engine Oil}

Microwave pyrolysis has recently shown excellent potential for recycling waste oil $[65,71,76,78]$. By pyrolysing the waste oil in a modified microwave oven in the presence of a bed of particulate-carbon as the microwave-absorbent, hydrocarbons (of smaller molecular size than those present in the waste oil) and $\mathrm{H}_{2}$ are generated and these have potential for use as either an energy source or industrial feedstock $[65,78]$. The waste oil is a poor microwave-absorbent on its own due to its non-polar nature, 
therefore it requires heating by contact with materials with high microwave absorbency in order to achieve pyrolytic thermal cracking [65].

The pyrolysis generated a high yield (88 wt.\%) of a condensable oil product that contains substantial concentrations of potentially valuable light aliphatic and aromatic hydrocarbons [71], and with fuel properties comparable to transport-grade fuels [65]. The oil product showed a high recovery of the calorific value present in the waste oil, is relatively contaminant free with a low content of sulphur, oxygen, and residue, and is almost entirely free of metals [76]. In addition, the oil product is reported to show a low toxic risk and contain negligible or minor amounts of toxic polycyclic aromatic hydrocarbons (PAHs) compounds [76], which was the case for oil products from conventional electric-heated pyrolysis of waste oil [26,79]. The authors claimed that the oil product could potentially be treated and upgraded to transport grade fuels, or added to petroleum refinery as a chemical feedstock for further processing, although further studies are needed to confirm these possibilities. Figure 3 shows a schematic representation of the generation of oil product comparable to commercial gasoline fuel from microwave pyrolysis of the waste oil.

Figure 3. Schematic representation of the generation of gasoline-like oil product from microwave pyrolysis of waste oil [65].

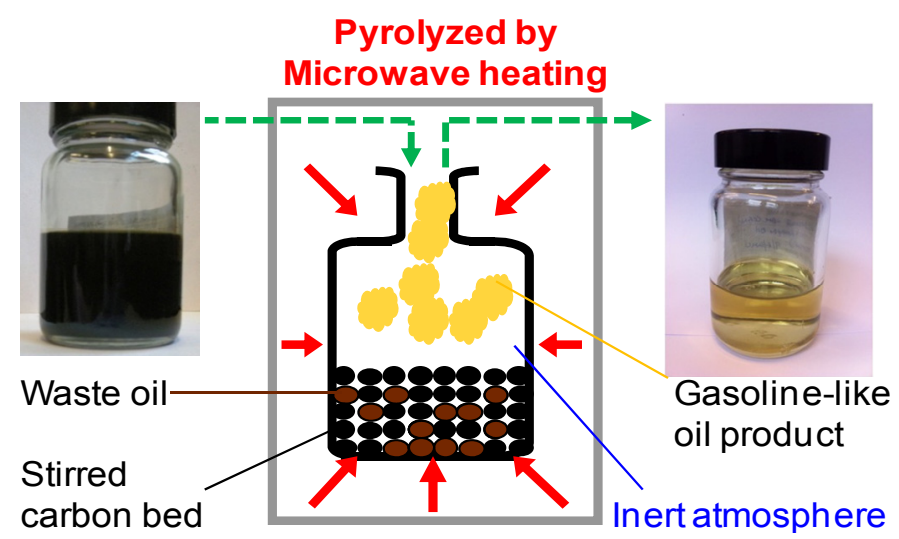

The pyrolysis process also produced an incondensable gaseous product that contains light aliphatic hydrocarbons and syngas that could potentially be used as a gaseous fuel and chemical feedstock [78]. In particular, the hydrogen obtained can be potentially used as a second-generation fuel or synthesis chemical, and the $\mathrm{CO}$ could be steam-reformed to produce more hydrogen. The light $\mathrm{C}_{2}-\mathrm{C}_{6}$ hydrocarbons generated can also be reformed easily to produce additional hydrogen or to be extracted for use as chemical feedstocks. The gaseous product could be burned directly in gas engine or fuel cells, or upgraded to produce hydrogen, and synthetic fuel (via Fischer-Tropsch process). Figure 4 shows a schematic representation of the generation of light aliphatic hydrocarbons and syngas from microwave pyrolysis of the waste oil. 
Figure 4. Schematic representation of the generation of light aliphatic hydrocarbons and syngas from microwave pyrolysis of waste oil [78].

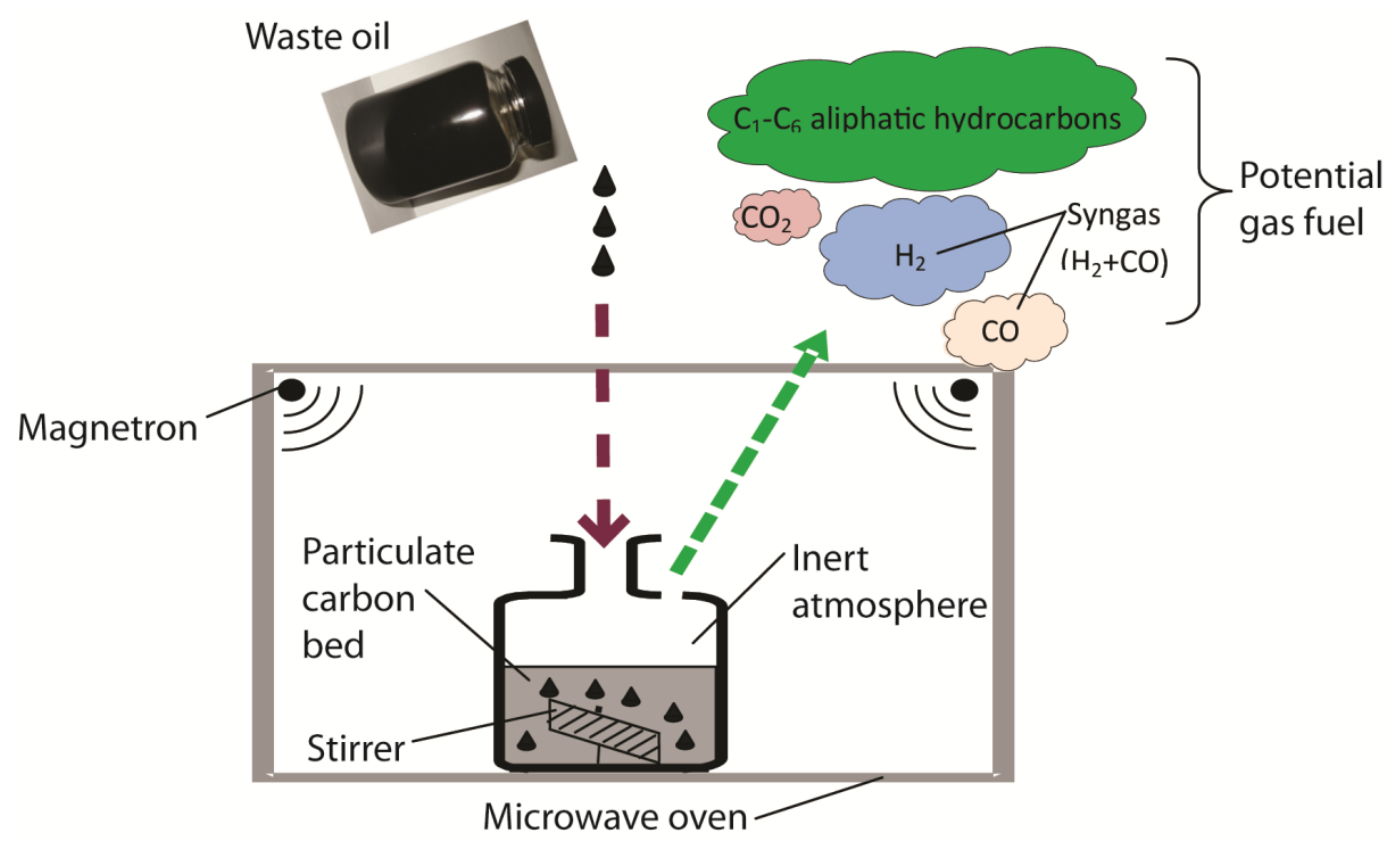

Additionally, the pyrolysis generated a char product that contained the majority of metals originally present in the waste oil, providing a convenient opportunity for the efficient recovery of these metals [76]. The char can be readily separated from the particulate-carbon particles by sieving, and the particulate-carbon bed can be repeatedly re-used as the microwave-absorbent (heating medium) after the separation, as a result of the fact that the majority of the metals were found to be present within the char particulates, resulting in very low levels of residual metals being retained within the particulate-carbon bed itself. The microwave apparatus was operated with an electrical power input of $7.5 \mathrm{~kW}$ and was capable of processing waste oil at a flow rate of $5 \mathrm{~kg} / \mathrm{h}$ with a positive energy ratio of 8 (energy content of hydrocarbon products/electrical energy supplied for microwave heating) and a net energy output of $179,390 \mathrm{~kJ} / \mathrm{h}[65]$.

The product compositions, which are different to those formed in conventional pyrolysis of oils, can be attributed to the unique heating mode and the chemical environment present during microwave pyrolysis, and chemical mechanisms for the production of the various products were proposed $[65,78]$. The authors demonstrated that microwave pyrolysis offers an exciting new approach to treat and transform the waste oil into valuable hydrocarbon feedstocks and gases.

\subsection{Plastic Wastes}

Microwave pyrolysis has been successfully applied to high density polyethylene using a stirred carbon bed, producing a high yield of oil/waxes $(80 \%)$ at $500{ }^{\circ} \mathrm{C}$ and $600{ }^{\circ} \mathrm{C}$ [7]. This work has been extended to aluminium-coated packaging waste, where the pyrolysis process was performed to separate aluminium from aluminium-coated polymer laminates found in toothpaste tubes and de-pulped drink-cartons (e.g., Tetrapacks) [7]. The process showed great promise as a separation technology as almost the entire aluminium fraction could be recovered from the waste packaging. 


\subsection{Biomass Wastes}

Sewage sludge is an environmentally hazardous, high-volume waste that has become a major concern for modern society. The existing disposal processes, such as landfilling and incineration, are becoming increasingly impracticable as concerns over environmental pollution and high treatment costs are recognised due to contaminants present in sewage sludge [35]. In addition, the high treatment costs are partly due to the need to remove the high amounts of water present in the sludge. In view of the limitation associated with current disposal methods, a great deal of studies has been performed to develop microwave pyrolysis as an alternative to treat and recycle sewage sludge [62,74,77,80,81]. In these studies, sewage sludge was mixed with small amounts of the char produced from previous runs and subjected to microwave pyrolysis treatment at $1040{ }^{\circ} \mathrm{C}$. The authors demonstrated that the use of microwave heating is effective in drying the sewage sludge during the initial stage of the pyrolysis process. Then, the steam produced by the microwave-induced drying could be used to gasify the products generated from the pyrolysis process. The authors claimed that the microwave pyrolysis method showed advantages over conventional pyrolysis in providing drying, pyrolysis, and gasification treatments to sewage sludge at the same time while generating a high yield of a gaseous product containing valuable syngas (up to 66 vol\%) and a small amount of oil product with a low content of PAHs. In contrast, they reported that the oil product obtained from conventional pyrolysis of sewage sludge contained mostly of PAHs. Tian et al. [72] have recently demonstrated the use of microwave pyrolysis to produce bio-oil from sewage sludge. The authors claimed that a high yield of bio-oil could be obtained at a microwave power ranging from 400 to $600 \mathrm{~W}$, and the bio-oil could potentially be used as a bio-fuel.

In addition to sewage sludge, microwave pyrolysis has been used to produce hydrogen rich fuel gas from coffee bean hulls [12], rice straw [69], straw bale [70]. The authors claimed that a high yield of gaseous product $(\sim 70 \mathrm{wt} \%)$ was obtained at a pyrolysis temperature of $1000{ }^{\circ} \mathrm{C}$. The gaseous product also showed a greater content of $\mathrm{H}_{2}(35-50 \mathrm{vol} \%)$ and syngas (50-72 vol\%) than that produced during conventional electric-heated pyrolysis under similar conditions (with a $\mathrm{H}_{2}$ content of $30 \mathrm{vol} \%$ and a syngas content of $53 \mathrm{vol} \%$ ).

Microwave pyrolysis has also been employed to convert wood block to tar (up to $30 \mathrm{wt} \%$ ), oil, and charcoal [82]. The diffuse nature of the electromagnetic field allows microwave heating to evenly heat many substances in bulk [61], and thus allowing the processing of large wood samples without the need of a pre-treatment process such as pulverisation. The author demonstrated that microwave pyrolysis showed advantages in providing a rapid heating and less power consumption when compared with conventional pyrolysis.

\subsection{Hazardous Waste Processing}

Microwave pyrolysis has also been successfully used to transform car tyres into carbon black, steel, liquid hydrocarbon oil, and gaseous hydrocarbons [75]. In addition, the pyrolysis has been applied to decontaminate oil-contaminated drill cuttings [33]. The authors demonstrated that the pyrolysis can be performed without the need for an appropriate intermediate microwave receptor, as the water present in the cuttings can directly be used as a microwave-absorbent to generate heat in order for pyrolysis to 
occur. However, the extent to which the process actually decontaminates the cuttings has yet to be fully investigated. Chlorodifluoromethane is another hazardous waste that has been processed using microwave pyrolysis in a microwave-heated fluidised bed [83]. The authors claimed that microwave pyrolysis showed advantages in providing a rapid heating process to pyrolyse the waste without overheating the reactor walls.

\subsection{Production of Synthetic Fuel}

Coal has been processed with microwave pyrolysis at high temperatures (up to $1300{ }^{\circ} \mathrm{C}$ ) using a variety of intermediate microwave receptors (i.e., coke, $\mathrm{Fe}_{3} \mathrm{O}_{4}, \mathrm{CuO}$ ) in order to produce condensable tars suitable for use as a fuel [39]. A $20 \mathrm{wt} \%$ yield of condensable tar was achieved in the presence of coke, whereas a yield of $27 \mathrm{wt} \%$ was recorded in the presence of $\mathrm{Fe}_{3} \mathrm{O}_{4}$, and a maximum yield of $49 \mathrm{wt} \%$ was obtained in the presence of $\mathrm{CuO}$. The authors claimed that coal (which is known to be a poor microwave-absorbent) can be efficiently processed with microwave pyrolysis in the presence of inorganic oxides as the microwave receptor, although the coal heats up slowly on its own when subjected to microwave radiation and is transformed into carbon black.

Oil shale is another material that has been processed by microwave pyrolysis at a temperature of $700{ }^{\circ} \mathrm{C}$, producing $6 \mathrm{wt} \%$ of oil product and $10 \mathrm{wt} \%$ of gaseous product [41]. The authors found that the product yields obtained by microwave pyrolysis were similar to those obtained by conventional pyrolysis, but they claimed that microwave pyrolysis promoted a different product composition as more cracking was observed and this resulted in production of lower amounts of polar, sulphur, and nitrogen compounds.

\section{Conclusions}

Up to now research in microwave pyrolysis has been centred on its application to treating wastes such as plastic waste [7], sewage sludge [74], scrap tyres [18], wood blocks [82], oil shales [41], and various organic wastes [84]. However, despite the variety of research that has been conducted on microwave pyrolysis, the growth of industrial microwave heating applications is hampered by an apparent lack of the understanding of microwave systems and the technical information for designing commercial equipment for these pyrolysis processes. Also, there have been no reports on the economic assessment of the microwave pyrolysis in order to determine the economic viability of the process, and limited information is available on the economic evaluation of the other pyrolysis processes in the literature, thus no economic comparisons have been made to date.

Consequently, despite the advantages shown by microwave pyrolysis, the use of this technology for waste treatment has not been extensively exploited. It was revealed that many important characteristics of the microwave pyrolysis process have yet to be raised or fully investigated, e.g., the influence of key process parameters on the yield and chemical composition of the product, the heating characteristic of a substance, and the production of any toxic compounds during the pyrolysis by microwave radiation. In addition, research on microwave pyrolysis has so far focused on pyrolysis performed in batch or semi-batch operation using typical process configurations that have also been used for conventional pyrolysis such as rotary kilns and fixed beds, where certain limitations of these processes have caused 
problems in treating real wastes such as waste oil. Thus, these limitations make it difficult for the pyrolysis processes to be optimized and demonstrated to be commercially attractive.

So far, there has been little research reported on the microwave pyrolysis of waste materials. It was established that current microwave pyrolysis techniques offer a number of advantages and show excellent potential for treating waste materials. However, it was found that such practice possesses limitations and uncertainties and there are still gaps to be filled in order to fully exploit the advantages of using microwave pyrolysis process in the treatment of waste materials. Hence, the main aim of using microwave pyrolysis is to provide an alternative pyrolysis process by making use of the high temperatures that the carbon bed can reach when subjected to a microwave field. This alternative way of heating is reported to have advantages over other conventional pyrolysis processes on account of better heat transfer to the waste materials, good control over the heating process as well as offering a very reducing chemical environment.

In summary, this literature review has revealed several aspects of microwave pyrolysis that need to be examined to investigate whether this particular pyrolysis technique is optimal for the treatment and energy recovery from waste materials. However, in view of mainly positive findings reported in the literature on the microwave pyrolysis studies, it would be worthwhile to carry on researching further aspects of microwave pyrolysis of waste materials in order to explore the full potential of this process. The optimisation of this process and the subsequent scale-up to a commercial scale will depend on how well the parameters involved in this new process and their relationships are understood.

\section{Acknowledgments}

Su Shiung Lam acknowledges the financial assistance by Public-Service-Department of Malaysia Government and University Malaysia Terengganu.

\section{References}

1. Latimer, J.S.; Hoffman, E.J.; Hoffman, G.; Fasching, J.L.; Quinn, J.G. Sources of petroleum-hydrocarbons in urban runoff. Water Air Soil Pollut. 1990, 52, 1-21.

2. Cormier, S.A.; Lomnicki, S.; Backes, W.; Dellinger, B. Origin and health impacts of emissions of toxic by-products and fine particles from combustion and thermal treatment of hazardous wastes and materials. Environ. Health Perspect. 2006, 114, 810-817.

3. Rowat, S.C. Incinerator toxic emissions: A brief summary of human health effects with a note on regulatory control. Med. Hypotheses 1999, 52, 389-396.

4. Dry, M.E. High quality diesel via the Fischer-Tropsch process-A review. J. Chem. Technol. Biotechnol. 2002, 77, 43-50.

5. Uçar, S.; Karagöz, S.; Yanik, J.; Saglam, M.; Yuksel, M. Copyrolysis of scrap tires with waste lubricant oil. Fuel Process. Technol. 2005, 87, 53-58.

6. Scheirs, J.; Kaminsky, W. Feedstock Recycling and Pyrolysis of Waste Plastics: Converting Waste Plastics into Diesel and Other Fuels; Wiley: Chichester, UK, 2006; Volume 27, pp. 2-785.

7. Ludlow-Palafox, C.; Chase, H.A. Microwave induced pyrolysis of plastic wastes. Ind. Eng. Chem. Res. 2001, 40, 4749-4756.

8. Dry, M.E. The Fischer-Tropsch process: 1950-2000. Catal. Today 2002, 71, 227-241. 
9. Song, G.-J.; Seo, Y.-C.; Pudasainee, D.; Kim, I.-T. Characteristics of gas and residues produced from electric arc pyrolysis of waste lubricating oil. Waste Manag. 2010, 30, 1230-1237.

10. Sinağ, A.; Gülbay, S.; Uskan, B.; Uçar, S.; Özgürler, S.B. Production and characterization of pyrolytic oils by pyrolysis of waste machinery oil. J. Hazard. Mater. 2010, 173, 420-426.

11. Onwudili, J.A.; Insura, N.; Williams, P.T. Composition of products from the pyrolysis of polyethylene and polystyrene in a closed batch reactor: Effects of temperature and residence time. J. Anal. Appl. Pyrolysis 2009, 86, 293-303.

12. Domínguez, A.; Menéndez, J.A.; Fernández, Y.; Pis, J.J.; Nabais, J.M.V.; Carrott, P.J.M.; Carrott, M.M.L.R. Conventional and microwave induced pyrolysis of coffee hulls for the production of a hydrogen rich fuel gas. J. Anal. Appl. Pyrolysis 2007, 79, 128-135.

13. Carlson, T.R.; Cheng, Y.-T.; Jae, J.; Huber, G.W. Production of green aromatics and olefins by catalytic fast pyrolysis of wood sawdust. Energy Environ. Sci. 2011, 4, 145-161.

14. Bridgwater, A.V. Review of fast pyrolysis of biomass and product upgrading. Biomass Bioenergy 2012, 38, 68-94.

15. Osepchuk, J.M. Microwave power applications. IEEE Trans. Microwave Theory Tech. 2002, 50, 975-985.

16. Marken, F.; Sur, U.K.; Coles, B.A.; Compton, R.G. Focused microwaves in electrochemical processes. Electrochim. Acta 2006, 51, 2195-2203.

17. Ramasamy, K.K.; T-Raissi, A. Hydrogen production from used lubricating oils. Catal. Today. 2007, 129, 365-371.

18. Ludlow-Palafox, C.; Chase, H.A. Microwave pyrolysis of plastic wastes. In Feedstock Recycling and Pyrolysis of Waste Plastics; Scheirs, J., Kaminsky, W., Eds.; John Wiley and Sons Ltd.: Chichester, UK, 2006; pp. 569-594.

19. Arpa, O.; Yumrutas, R.; Demirbas, A. Production of diesel-like fuel from waste engine oil by pyrolitic distillation. Appl. Energy 2010, 87, 122-127.

20. Fuentes, M.J.; Font, R.; Gómez-Rico, M.F.; Martín-Gullón, I. Pyrolysis and combustion of waste lubricant oil from diesel cars: Decomposition and pollutants. J. Anal. Appl. Pyrol. 2007, 79, 215-226.

21. Balat, M.; Demirbas, M.F. Pyrolysis of waste engine oil in the presence of wood ash. Energy Sources Part A 2009, 31, 1494-1499.

22. Kim, Y.S.; Jeong, S.U.; Yoon, W.L.; Yoon, H.K.; Kim, S.H. Tar-formation kinetics and adsorption characteristics of pyrolyzed waste lubricating oil. J. Anal. Appl. Pyrolysis 2003, 70, 19-33.

23. Kim, S.S.; Chun, B.H.; Kim, S.H. Non-isothermal pyrolysis of waste automobile lubricating oil in a stirred batch reactor. Chem. Eng. J. 2003, 93, 225-231.

24. Juniper Consultancy Services Ltd. Pyrolysis and Gasification of Wastes; Juniper Consultancy Services Ltd.: London, UK, 1997.

25. Williams, P.T.; Besler, S. Polycyclic aromatic hydrocarbons in waste derived pyrolytic oils. J. Anal. Appl. Pyrolysis 1994, 30, 17-33.

26. Domeño, C.; Nerín, C. Fate of polyaromatic hydrocarbons in the pyrolysis of industrial waste oils. J. Anal. Appl. Pyrolysis 2003, 67, 237-246.

27. Lázaro, M.J.; Moliner, R.; Suelves, I.; Nerín, C.; Domeño, C. Valuable products from mineral waste oils containing heavy metals. Environ. Sci. Technol. 2000, 34, 3205-3210. 
28. Holland, K.M. Apparatus for Waste Pyrolysis. U.S. Patent 5,387,321, 7 February 1995.

29. Holland, K.M. Process of Destructive Distillation of Organic Material. U.S. Patent 5,330,623, 19 July 1994.

30. Bilali, L.; Benchanaa, M.; El harfi, K.; Mokhlisse, A.; Outzourhit, A. A detailed study of the microwave pyrolysis of the Moroccan (Youssoufia) rock phosphate. J. Anal. Appl. Pyrolysis 2005, 73, 1-15.

31. Li, H.; Liao, L.; Liu, L. Kinetic Investigation into the Non-thermal microwave effect on the ring-opening polymerization of E-Caprolactone. Macromol. Rapid Commun. 2007, 28, 411-416.

32. Meredith, R. Engineers' Handbook of Industrial Microwave Heating; The Institution of Electrical Engineers: London, UK, 1998.

33. Robinson, J.; Snape, C.; Kingman, S.; Shang, H. Thermal desorption and pyrolysis of oil contaminated drill cuttings by microwave heating. J. Anal. Appl. Pyrolysis 2008, 81, 27-32.

34. Metaxas, A.C. Foundations of Electroheat; John Wiley and Sons Ltd.: Chichester, UK, 1996.

35. Menéndez, J.A.; Arenillas, A.; Fidalgo, B.; Fernández, Y.; Zubizarreta, L.; Calvo, E.G.; Bermúdez, J.M. Microwave heating processes involving carbon materials. Fuel Process. Technol. 2010, $91,1-8$.

36. Zhang, X.; Hayward, D.O. Applications of microwave dielectric heating in environment-related heterogeneous gas-phase catalytic systems. Inorg. Chim. Acta 2006, 359, 3421-3433.

37. Udalov, E.; Bolotov, V.; Tanashev, Y.; Chernousov, Y.; Parmon, V. Pyrolysis of liquid hexadecane with selective microwave heating of the catalyst. Theor. Exp. Chem. 2011, 46, 384-392.

38. Menéndez, J.A.; Domínguez, A.; Fernández, Y.; Pis, J.J. Evidence of Self-Gasification during the Microwave-Induced Pyrolysis of Coffee Hulls. Energy Fuel. 2007, 21, 373-378.

39. Monsef-Mirzai, P.; Ravindran, M.; McWhinnie, W.R.; Burchill, P. Rapid microwave pyrolysis of coal: Methodology and examination of the residual and volatile phases. Fuel 1995, 74, $20-27$.

40. Monsef-Mirzai, P.; Ravindran, M.; McWhinnie, W.R.; Burchil, P. The use of microwave heating for the pyrolysis of coal via inorganic receptors of microwave energy. Fuel 1992, 71, 716-717.

41. El harfi, K.; Mokhlisse, A.; Chanaa, M.B.; Outzourhit, A. Pyrolysis of the Moroccan (Tarfaya) oil shales under microwave irradiation. Fuel 2000, 79, 733-742.

42. Fernández, Y.; Arenillas, A.; Díez, M.A.; Pis, J.J.; Menéndez, J.A. Pyrolysis of glycerol over activated carbons for syngas production. J. Anal. Appl. Pyrolysis 2009, 84, 145-150.

43. Menéndez, J.A.; Inguanzo, M.; Pis, J.J. Microwave-induced pyrolysis of sewage sludge. Water Res. 2002, 36, 3261-3264.

44. Menéndez, J.A.; Menéndez, E.M.; Garcia, A.; Parra, J.B.; Pis, J.J. Thermal treatment of active carbons: A comparison between microwave and electrical heating. Int. Microwave Power Inst. 1999, 34, 137-143.

45. Liu, C.C.; Walters, A.; Vannice, M. Measurement of electrical properties of a carbon black. Carbon 1995, 33, 1699-1708.

46. Fidalgo, B.; Arenillas, A.; MenÈndez, J.A. Influence of porosity and surface groups on the catalytic activity of carbon materials for the microwave-assisted $\mathrm{CO}_{2}$ reforming of $\mathrm{CH}_{4}$. Fuel 2010, 89, 4002-4007.

47. Roberts, B.A.; Strauss, C.R. Toward rapid, "green", predictable microwave-assisted synthesis. Acc. Chem. Res. 2005, 38, 653-661. 
48. Nuchter, M.; Ondruschka, B.; Bonrath, W.; Gum, A. Microwave assisted synthesis-A critical technology overview. Green Chem. 2004, 6, 128-141.

49. Strauss, C.; Rooney, D. Accounting for clean, fast and high yielding reactions under microwave conditions. Green Chem. 2010, 12, 1340-1344.

50. Fantini, M.; Zuliani, V.; Spotti, M.A.; Rivara, M. Microwave assisted efficient synthesis of imidazole-based privileged structures. J. Comb. Chem. 2009, 12, 181-185.

51. De Paolis, O.; Teixeira, L.; Török, B. Synthesis of quinolines by a solid acid-catalyzed microwave-assisted domino cyclization-aromatization approach. Tetrahedron Lett. 2009, 50, 2939-2942.

52. Herrero, M.A.; Kremsner, J.M.; Kappe, C.O. Nonthermal microwave effects revisited: On the importance of internal temperature monitoring and agitation in microwave chemistry. J. Org. Chem. 2007, 73, 36-47.

53. Hosseini, M.; Stiasni, N.; Barbieri, V.; Kappe, C.O. Microwave-assisted asymmetric organocatalysis. A probe for nonthermal microwave effects and the concept of simultaneous cooling. J. Org. Chem. 2007, 72, 1417-1424.

54. De la Hoz, A.; Diaz-Ortiz, A.; Moreno, A. Microwaves in organic synthesis. Thermal and non-thermal microwave effects. Chem. Soc. Rev. 2005, 34, 164-178.

55. Schmink, J.R.; Leadbeater, N.E. Probing "microwave effects" using Raman spectroscopy. Org. Biomol. Chem.2009, 7, 3842-3846.

56. Razzaq, T.; Kremsner, J.M.; Kappe, C.O. Investigating the existence of nonthermal/specific microwave effects using silicon carbide heating elements as power modulators. J. Org. Chem. 2008, 73, 6321-6329.

57. Bagnell, L.; Cablewski, T.; Strauss, C.R.; Trainor, R.W. Reactions of allyl phenyl ether in high-temperature water with conventional and microwave heating. J. Org. Chem. 1996, 61, 7355-7359.

58. Jones, D.A.; Lelyveld, T.P.; Mavrofidis, S.D.; Kingman, S.W.; Miles, N.J. Microwave heating applications in environmental engineering-A review. Resour. Conserv. Recycl. 2002, 34, 75-90.

59. Fernández, Y.; Arenillas, A.; Bermúdez, J.M.; Menéndez, J.A. Comparative study of conventional and microwave-assisted pyrolysis, steam and dry reforming of glycerol for syngas production, using a carbonaceous catalyst. J. Anal. Appl. Pyrolysis 2010, 88, 155-159.

60. Appleton, T.J.; Colder, R.I.; Kingman, S.W.; Lowndes, I.S.; Read, A.G. Microwave technology for energy-efficient processing of waste. Appl. Energy 2005, 81, 85-113.

61. Lei, H.; Ren, S.; Julson, J. The effects of reaction temperature and time and particle size of corn stover on microwave pyrolysis. Energy Fuel. 2009, 23, 3254-3261.

62. Menéndez, J.A.; Domínguez, A.; Inguanzo, M.; Pis, J.J. Microwave pyrolysis of sewage sludge: Analysis of the gas fraction. J. Anal. Appl. Pyrolysis 2004, 71, 657-667.

63. Committee on Microwave Processing of Materials: An Emerging Industrial Technology, National Materials Advisory Board, Commission on Engineering and Technical Systems and National Research Council (US). Microwave Processing of Materials; National Academy Press: Washington, DC, USA, 1994; Volume 473. 
64. Du, Z.; Li, Y.; Wang, X.; Wan, Y.; Chen, Q.; Wang, C.; Lin, X.; Liu, Y.; Chen, P.; Ruan, R. Microwave-assisted pyrolysis of microalgae for biofuel production. Bioresour. Technol. 2011, 102, 4890-4896.

65. Lam, S.S.; Russell, A.D.; Lee, C.L.; Chase, H.A. Microwave-heated pyrolysis of waste automotive engine oil: Influence of operation parameters on the yield, composition, and fuel properties of pyrolysis oil. Fuel 2012, 92, 327-339.

66. Lázaro, M.J.; Moliner, R.; Suelves, I.; Domeño, C.; Nerín, C. Co-pyrolysis of a mineral waste oil/coal slurry in a continuous-mode fluidized bed reactor. J. Anal. Appl. Pyrolysis 2002, 65, 239-252.

67. Demirbas, A. Gasoline-like fuel from waste engine oil via catalytic pyrolysis. Energy Sources Part A 2008, 30, 1433-1441.

68. Domínguez, A.; Menéndez, J.A.; Inguanzo, M.; Pis, J.J. Investigations into the characteristics of oils produced from microwave pyrolysis of sewage sludge. Fuel Process. Technol. 2005, 86, 1007-1020.

69. Huang, Y.F.; Kuan, W.H.; Lo, S.L.; Lin, C.F. Hydrogen-rich fuel gas from rice straw via microwave-induced pyrolysis. Bioresour.Technol. 2010, 101, 1968-1973.

70. Zhao, X.; Zhang, J.; Song, Z.; Liu, H.; Li, L.; Ma, C. Microwave pyrolysis of straw bale and energy balance analysis. J. Anal. Appl. Pyrolysis 2011, 92, 43-49.

71. Lam, S.S.; Russell, A.D.; Chase, H.A. Microwave pyrolysis, a novel process for recycling waste automotive engine oil. Energy 2010, 35, 2985-2991.

72. Tian, Y.; Zuo, W.; Ren, Z.; Chen, D. Estimation of a novel method to produce bio-oil from sewage sludge by microwave pyrolysis with the consideration of efficiency and safety. Bioresour. Technol. 2011, 102, 2053-2061.

73. Zuo, W.; Tian, Y.; Ren, N. The important role of microwave receptors in bio-fuel production by microwave-induced pyrolysis of sewage sludge. Waste Manag. 2011, 31, 1321-1326.

74. Domínguez, A.; Fernández, Y.; Fidalgo, B.; Pis, J.J.; Menéndez, J.A. Bio-syngas production with low concentrations of $\mathrm{CO}_{2}$ and $\mathrm{CH}_{4}$ from microwave-induced pyrolysis of wet and dried sewage sludge. Chemosphere 2008, 70, 397-403.

75. Yatsun, A.; Konovalov, P.; Konovalov, N. Gaseous products of microwave pyrolysis of scrap tires. Solid Fuel Chem. 2008, 42, 187-191.

76. Lam, S.S.; Russell, A.D.; Chase, H.A. Pyrolysis using microwave heating: A sustainable process for recycling used car engine oil. Ind. Eng. Chem. Res. 2010, 49, 10845-10851.

77. Domínguez, A.; Menéndez, J.A.; Inguanzo, M.; Pís, J.J. Production of bio-fuels by high temperature pyrolysis of sewage sludge using conventional and microwave heating. Bioresour. Technol. 2006, 97, 1185-1193.

78. Lam, S.S.; Russell, A.D.; Lee, C.L.; Lam, S.K.; Chase, H.A. Production of hydrogen and light hydrocarbons as a potential gaseous fuel from microwave-heated pyrolysis of waste automotive engine oil. Int. J. Hydrog. Energy 2012, 37, 5011-5021.

79. Nerin, C.; Domeno, C. Determination of polyaromatic hydrocarbons and some related compounds in industrial waste oils by GPC-HPLC-UV. Analyst 1999, 124, 67-70.

80. Menendez, J.A.; Dominguez, A.; Inguanzo, M.; Pis, J.J. Microwave-induced drying, pyrolysis and gasification (MWDPG) of sewage sludge: Vitrification of the solid residue. J. Anal. Appl. Pyrolysis 2005, 74, 406-412. 
81. Domínguez, A.; Menéndez, J.A.; Inguanzo, M.; Bernad, P.L.; Pis, J.J. Gas chromatographic-mass spectrometric study of the oil fractions produced by microwave-assisted pyrolysis of different sewage sludges. J. Chromatogr. A 2003, 1012, 193-206.

82. Miura, M.; Kaga, H.; Sakurai, A.; Kakuchi, T.; Takahashi, K. Rapid pyrolysis of wood block by microwave heating. J. Anal. Appl. Pyrolysis 2004, 71, 187-199.

83. Kim, H.C.; Kim, H.Y.; Woo, S.I. Fast pyrolysis of chlorodifluoromethane in a microwave-heated fluidized bed. J. Chem. Eng. Jpn. 1999, 32, 171-176.

84. Chemat, F.; Poux, M. Microwave assisted pyrolysis of urea supported on graphite under solvent-free conditions. Tetrahedron Lett. 2001, 42, 3693-3695.

(C) 2012 by the authors; licensee MDPI, Basel, Switzerland. This article is an open access article distributed under the terms and conditions of the Creative Commons Attribution license (http://creativecommons.org/licenses/by/3.0/). 